\title{
Efecto de la alta presión hidrostática en la exposición del contenido de sulfhidrilos libres en amilasa fúngica
}

\section{Effect of high hydrostatic pressure on free sulfhydryl content from fungal a-amylase}

Ormando, Paula (1, 2); Vranic, María L. (1, 3); Guidi, Silvina (1, 4), Ambrosi, Vanina $(1,5)$.

(1) Instituto Tecnología de Alimentos (ITA), CIA, Instituto Nacional de Tecnología Agropecuaria (INTA), Argentina.

(2) Instituto de Tecnología, Fundación UADE. Universidad Argentina de la Empresa, Buenos Aires, Argentina.

(3) Departamento de Tecnología. Universidad de Luján (UNLu). Luján, Buenos Aires, Argentina.

(4) Facultad de Agronomía y Ciencias Agroalimentarias. Universidad de Morón (UM). Morón, Buenos Aires, Argentina.

(5) Facultad de Farmacia y Bioquímica (FFyB). Universidad de Buenos Aires (UBA). CABA, Buenos Aires, Argentina.

Contacto: paulaormando@gmail.com

RECIBIDO: $16 / 3 / 2018$ - APROBADO: $15 / 6 / 2018$

\begin{abstract}
Resumen
El objetivo de este trabajo fue evaluar el efecto térmico residual generado luego del uso en ciclos consecutivos del equipo de Alta Presión Hidrostática (APH) en tres posiciones internas (superior, central e inferior) mediante la cuantificación del contenido de sulfhidrilos libres [SH-L] de a-amilasa de Aspergillus oryzae expresado en $\mu$ mol de $\mathrm{SH} / \mathrm{g}$ de proteína. La potencial utilización de la cuantificación de [SH-L] de la enzima como indicador de tratamiento de APH permite medir en forma indirecta el efecto térmico durante el proceso.

En el ensayo se utilizó un equipo de APH de 2L con alimentación inferior del fluido de presurización (agua:propilenglicol-70:30v/v). En cada ciclo, el fluido a temperatura ambiente fue comprimido hasta alcanzar la presión deseada (605 MPa), y el nivel de presión se mantuvo durante cinco minutos con posterior despresurización. El ciclo fue repetido tres veces en forma consecutiva.

Se realizó un ANOVA $(\alpha=0,05)$ correspondiente a un diseño factorial de dos factores: posiciones y ciclos consecutivos, con tres niveles cada uno, y con cuatro repeticiones para el diseño completo. Se obtuvieron diferencias significativas en la interacción ciclo* ${ }^{*}$ osición ( $p$ valor $=0,001$ ) y el ciclo ( $p$ valor=0,021). Estos resultados evidencian el efecto del calor generado durante la compresión adiabática, afectando la historia térmica de la a-amilasa. Dada su sensibilidad, esta enzima podría ser considerada a futuro como un indicador de procesos de APH que permite evaluar la diferencia entre las muestras procesadas durante los ciclos, y que evidencia el perfil térmico generado dentro del equipo. Palabras clave: Altas Presiones, contenido de sulfhidrilos libres, amilasa.
\end{abstract}

\begin{abstract}
We evaluated the residual thermal effect generated by the consecutive High Hydrostatic Pressure (HHP) cycles relative to the position (upper, central and lower) inside a high pressure vessel determining the free sulfhydryl groups [F-SH] from pressurized a-amylase Aspergillus oryzae expressed in $\mu \mathrm{mol} \mathrm{SH} / g$ protein. This methodology could represent a potential indicator of HHP treatment, allowing to measure in an indirect way the thermal effect during the process. Assays were carried out using a $2 \mathrm{~L}$ stabilized lab scale equipment, where pressurizing medium (water-propilenglycol:70-30\%) was injected at room temperature from the bottom of the vessel.

For each cycle, the fluid at room temperature was compressed until reaching the desired pressure (605 MPa), maintained for five minutes, followed by depressurization. The cycle was repeated three consecutive times.

The free sulfhydryl content was assayed statistically using one-way ANOVA $(\alpha=0,05)$ for a factorial design of two factors: positions and consecutive cycles, with three levels, and four repetitions for the complete design. Significant differences were obtained in the interaction cycles $^{\star}$ position (pvalue $=0,001$ ) and cycles (pvalue $=0,021$ ).

These results demonstrate the effect of the heat generation during adiabatic compression, affecting the thermal history of the $\alpha$-amylase. Due to its sensitivity to pressure, this enzyme could be considered as a potential indicator of high pressure processing in the future, evaluating the difference between processed samples during cycles, and confirming the thermal profile generated within the equipment.

Keywords: High Pressure, free sulfhydryl content, amylase.
\end{abstract}




\section{Introducción}

Entre las tecnologías no térmicas, la tecnología de Altas Presiones Hidrostáticas (APH) es la que mayor aplicación comercial ha alcanzado en las últimas dos décadas. Se aplica a nivel industrial para pasteurizar tanto alimentos de origen vegetal, como jugos de frutas y mermeladas, y en productos de origen animal, como el jamón cocido/curado, pescados y mariscos, además de aderezos y salsas. Cabe destacar que los componentes de bajo peso molecular, responsables de las características nutricionales y sensoriales como el aroma y el sabor, no son afectados (Welti-Chanes, et al., 2005; Hugas, et al., 2002), así como tampoco el aspecto general y la frescura.

En equipos que se utilizan en los laboratorios o en una planta piloto, durante el procesamiento por APH se aplica una presión comprendida entre 50 y $1000 \mathrm{MPa}$, mediante un líquido, generalmente agua o mezclas de alcoholes y agua, cuya temperatura se encuentra en el rango de $-40^{\circ} \mathrm{C}$ a $110^{\circ} \mathrm{C}$. Los alimentos son envasados en envases flexibles y herméticos, y son colocados en una cámara de presurización metálica con paredes de gran espesor. A nivel industrial, la máxima presión que se aplica es 600 a $800 \mathrm{MPa}$, a temperatura ambiente o de refrigeración. Una vez realizada la carga de los alimentos, se cierra la cámara y se eliminan los gases. Posteriormente, se mantiene bajo presión durante un período (minutos) y luego se realiza la despresurización del sistema y la descarga del producto. Sin embargo, durante la primera etapa del proceso, el fluido de presurización sufre un incremento de temperatura por compresión adiabática (efecto conjunto de presión y temperatura). Este incremento puede ser diferente según la posición dentro del equipo APH que se considere (Ormando et al., 2015, 2017).

Cuando el fluido de presurización es agua, el incremento de temperatura es de 2 a $3{ }^{\circ} \mathrm{C}$ por cada $100 \mathrm{MPa}$ (Makita, 1992). No obstante, cuando se emplean mezclas con solventes orgánicos y/o aceites como fluido de presurización, el aumento de temperatura es mayor, debido a que estos poseen un mayor valor de compresibilidad, una menor conductividad térmica y capacidad calorífica con respecto al agua (Balasubramanian y Balasubramaniam, 2003; Ormando, et al., 2015, 2016).

De acuerdo al Principio de Pascal, la presión se presupone uniforme dentro de un material homogéneo $y$, al tratarse de un proceso tipo batch o por lotes, el tiempo de procesamiento o residencia es fijo. En este sentido, Hartmann y Delgado (2003) informaron que durante la compresión se desarrolla un campo de velocidades del fluido por efecto de la convección forzada, mientras que durante la fase de mantenimiento de la presión se produce el fenómeno de convección natural. El movimiento del fluido de presurización genera condiciones térmicas no uniformes, especialmente cuando el fluido es altamente viscoso, ya que disminuye el movimiento convectivo. Considerando el efecto sobre la inocuidad, los atributos de calidad sensorial, nutricional y la extensión de la vida útil de los alimentos, los parámetros de proceso más importantes en el tratamiento con APH son: el nivel de presión (P), el tiempo de mantenimiento (t) y la temperatura (T). Durante la compresión del fluido de presurización se genera calor, que produce el aumento de la temperatura del fluido y del alimento. Según estudios realizados por Rasanayagam et al. (2003), el incremento de temperatura depende: del máximo nivel presión alcanzado en el proceso, de la temperatura inicial, del tipo de fluido de presurización elegido, de la compresibilidad y de la capacidad calorífica del fluido de compresión y del alimento tratado con APH, que en ambos casos depende de la composición.
Para evaluar la distribución de temperatura en el cilindro de APH se pueden utilizar diferentes estrategias. Una manera efectiva es utilizar termocuplas ( $\mathrm{T}$ o K), que se ubican ya sea en las diferentes posiciones del cilindro como en muestras a analizar, sin que afecten la circulación del fluido dentro del cilindro. En este sentido, Ormando et al. $(2015,2016)$ evaluaron en un equipo de APH de $2 \mathrm{~L}$ los perfiles térmicos para tres posiciones (superior, central e inferior) sometidos a presiones de 205, 405 y $605 \mathrm{MPa}$. Los resultados mostraron que la posición superior es aquella con mayor incremento de temperatura $\left(12,0 \pm 5,9^{\circ} \mathrm{C}\right)$ para $605 \mathrm{MPa}$ dentro del cilindro. En general, los incrementos de temperatura aumentan con la presión y la altura y disminuyen con el radio. Estos autores indicaron que la zona de mayor incremento térmico durante el ciclo de APH corresponde a la región central superior del equipo. El perfil heterogéneo de temperaturas registrado coincide con los resultados informados por Kitsubun et al. (2005) y Hartmann y Delgado (2003).

Otra metodología empleada es la llamada integradores dependientes de presión temperatura y tiempo (pTTI's por su sigla en inglés). Los pTTI's pueden ser definidos como pequeños dispositivos (proteínas aisladas o enzimas, coenzimas o inhibidores como integradores proteicos) que permiten medir en forma precisa e indirecta el efecto de un tratamiento de APH (Van der Plancken, et al., 2008). La selección y utilización de estos dispositivos se fundamenta en su actual disponibilidad en el mercado, en su bajo costo y en la escasa cantidad que se necesita para su análisis, por ejemplo $\mathrm{mg} / \mathrm{ml}$. Una de las ventajas de la utilización de enzimas es que tanto su actividad biológica como su nivel de desplegamiento son cuantificables mediante ensayos espectrofotométricos, en los cuales los resultados obtenidos dependerán principalmente del efecto de la aplicación de un tratamiento determinado. El efecto de la presión sobre la estructura y las propiedades funcionales de las proteínas se debe a cambios en las interacciones intra e intermoleculares entre los grupos funcionales de los aminoácidos. La presurización promueve la formación de enlaces entre las cadenas laterales (Hoover, et al., 1989), causando la modificación estructural reversible o irreversible en las proteínas, que conduce a su desnaturalización, agregación o gelatinización (Mills, et al., 2009).

A presiones de 300 y $400 \mathrm{MPa}$ se destacan efectos como el aumento de las interacciones hidrofóbicas, debido a la alta compresibilidad del agua libre comparada con la de los puentes hidrógeno. Por otra parte, los grupos sulfhidrilos pueden oxidarse dando lugar a puentes disulfuro en presencia de oxígeno (Funtenberger, et al., 1995). La aplicación de presión superior a 100-200 MPa a temperatura ambiente produce la disociación de macroestructuras en subunidades, así como el despliegue y la desnaturalización de las estructuras monoméricas, debido al debilitamiento de las interacciones hidrofóbicas y a la separación de puentes salinos inter o intramoleculares. Si la presión y la concentración de la proteína son elevadas, puede causar que las proteínas adopten una estructura más compacta, aunque la pérdida de su estructura secundaria es un fenómeno que solamente se manifiesta a presiones extremas (Cheftel, 1995). La alta presión induce la gelificación a baja temperatura, y en esas condiciones se obtienen geles de características distintas de las de los obtenidos por calor. En general, los efectos que sufren las estructuras terciarias y cuaternarias pueden ser reversibles, aunque dependen de factores como la temperatura y el $\mathrm{pH}$ del medio (Cheftel, 1995). 
Denys et al. (2000) fueron los primeros en utilizar pTTI's para la detección de los gradientes de temperatura dentro de la cámara de APH. En este sentido, Grauwet et al. (2010) evaluaron la distribución de temperaturas en un equipo APH horizontal (400-600 MPa; $\left.10-40{ }^{\circ} \mathrm{C} ; 1-15 \mathrm{~min}\right)$ utilizando enzimas a-amilasas bacterianas, cuya desnaturalización térmica ocurre por encima de los $80^{\circ} \mathrm{C}$. En este trabajo se utilizó $\alpha$-amilasa fúngica, ya que posee una susceptibilidad térmica mayor que la $\alpha$-amilasa bacteriana y se desnaturaliza por encima de los $60^{\circ} \mathrm{C}$, y tiene un costo comercial inferior. Se trata de una proteína monomérica que consta de una sola cadena polipeptídica de 478 aminoácidos con cuatro puentes disulfuro intracatenarios y un peso molecular de $51-53 \mathrm{kDa}$. La molécula está compuesta por un dominio mayor que contiene el sitio activo y un dominio C-terminal de menor tamaño (Fogarty y Kelly, 1983).

El objetivo de este trabajo fue evaluar el efecto térmico residual generado luego del uso en ciclos consecutivos del equipo de Alta Presión Hidrostática (APH), en tres posiciones internas (superior, central e inferior), mediante la cuantificación del contenido de sulfhidrilos libres [SH-L] de $\alpha$-amilasa de Aspergillus oryzae expresado en $\mu \mathrm{mol}$ de $\mathrm{SH} / \mathrm{g}$ de proteína.

\section{Materiales y Métodos}

\section{Preparación del extracto enzimático}

Se preparó una solución de una concentración $10 \mathrm{mg} / \mathrm{mL}$ de la enzima $\alpha$-amilasa de Aspergillus oryzae (A-9857, Sigma Aldrich, Alemania) en buffer 0,01M Tris-HCL, $\mathrm{pH} 8,6$. Las muestras se envasaron en bolsas termoselladas (Cryovac $(\mathrm{CN}-640) ; 2 \mathrm{~cm} \times 2,5 \mathrm{~cm})$ con un volumen final de $1 \mathrm{~mL}$, y posteriormente fueron colocadas en una segunda bolsa termosellada (Cryovac (CN-640); $5 \mathrm{~cm}$ x $6 \mathrm{~cm}$ ) y envasadas al vacío (Maximax 800, Rapivac, Argentina).

\section{Tratamiento de Altas Presiones Hidrostáticas (APH)}

Se utilizó un equipo APH escala laboratorio (Stansted Fluid Power Ltd., modelo Iso-Lab-S-IL-070-550-09-W, Stansted, Reino Unido) de configuración vertical que opera en forma discontinua. Este equipo cuenta con un cilindro de alta presión de 2 L de capacidad, encamisado por una cámara de intercambio de calor (Figura $1^{\text {a }}$ ), en la cual se ubica una canasta cilíndrica de $500 \mathrm{~mm}$ de altura $\times 70 \mathrm{~mm}$ de diámetro interno, donde el fluido de presurización (agua:propilenglicol-70:30v/v) es alimentado inferiormente, y una termocupla tipo $(\mathrm{K})$ que monitorea la temperatura de proceso y permite trabajar en un rango de temperatura de entre -20 a $130{ }^{\circ} \mathrm{C}$. La velocidad de compresión utilizada fue de $300 \mathrm{MPa} / \mathrm{min}$. En este ensayo se monitorearon mediante termocuplas tipo $\mathrm{K}$ tanto las temperaturas del fluido de presurización, como las temperaturas en las tres diferentes posiciones donde se ubicaron las muestras enzimáticas (superior, central e inferior).

Se monitorearon y registraron las evoluciones de temperatura vs. tiempo durante las diferentes etapas del proceso operativo: compresión - incremento de la presión hasta $605 \mathrm{MPa}$ - mantenimiento isobárico (5 minutos a presión constante) - descompresión hasta alcanzar la presión atmosférica $(0,1 \mathrm{MPa})$.

\section{Procesamiento de muestras de enzimas mediante APH}

Las muestras de enzimas sin procesar, envasadas en bolsas al vacío, fueron ingresadas a la canasta del equipo mediante un dispositivo centrado y conectado en su cabezal superior, ubicadas en sus respectivas posiciones (superior, central e inferior). La Figura $1 \mathrm{~b}$ indica las posiciones evaluadas dentro de la canasta del equipo de APH.

Para el ciclo I, una vez ingresadas las muestras se procedió a la presurización del fluido hasta alcanzar $605 \mathrm{MPa}$; este nivel de presión se mantuvo por cinco minutos y luego se despresurizó hasta alcanzar la presión atmosférica. Una vez finalizado el ciclo I, las muestras fueron retiradas del dispositivo dentro de la canasta y se reservaron en frío para su posterior análisis. Los ciclos II y III se llevaron a cabo de manera análoga y consecutiva.

\section{Determinación de sulfhidrilos libres}

Se tomaron $0,5 \mathrm{~mL}$ de cada una de las muestras tratadas (posiciones (superior, central e inferior) para los ciclos I, II y III), y

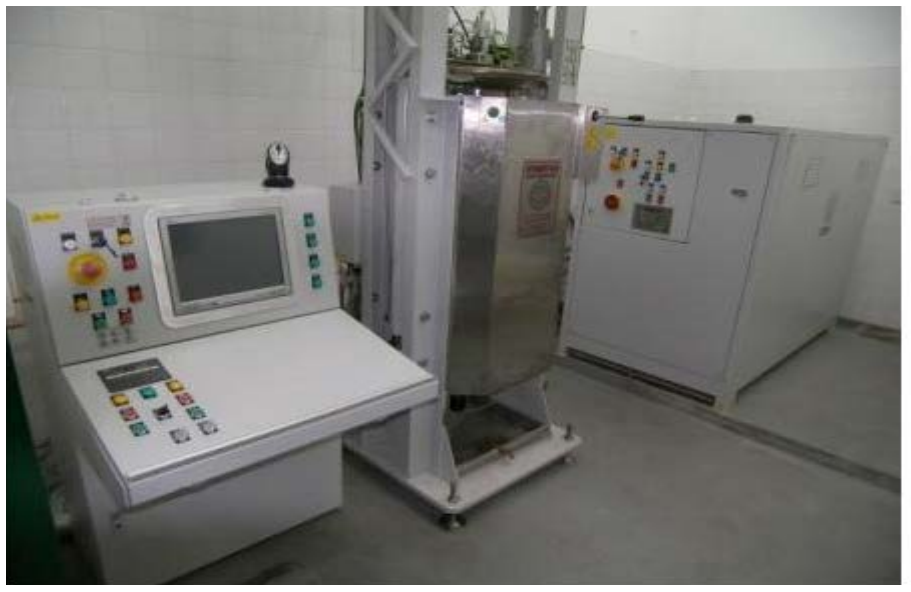

(a)

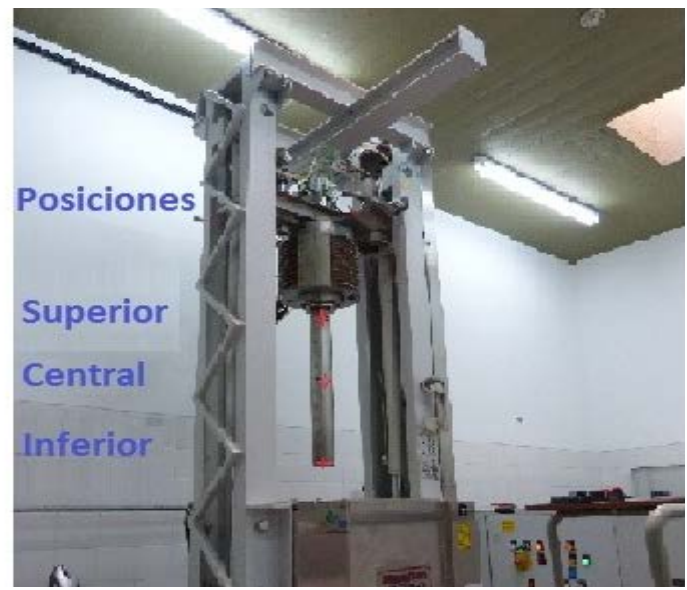

(b)

Figura 1. Equipo de APH a escala laboratorio (a) y posiciones de la canasta interna del equipo (b). 
se les adicionó $1,5 \mathrm{~mL}$ de buffer Tris-Glicina (1 M Tris, 0,1 M Glicina y 4 mM EDTA; pH 8,0) y $15 \mu \mathrm{l}$ del Reactivo de Ellman ( $4 \mathrm{mg} / \mathrm{mL}$ DTNB en Buffer Tris-Glicina). Seguidamente, se incubó la mezcla durante 30 minutos. El contenido de [SHL] se midió a $412 \mathrm{~nm}$ en un espectrofotómetro UV-visible (SpectroStar Nano, BMG Labtech GmbH, Alemania).

El coeficiente de extinción molar utilizado fue $13.600 \mathrm{M}^{-1}$ $\mathrm{cm}^{-1}$. La concentración de SH-L fue expresada como $\mu \mathrm{mol}$ de SH/g de proteína (Ellman, 1959).

La obtención del valor de la concentración se obtuvo a partir de la siguiente expresión:

[SH-L]: $\left(75,53\left(\mathrm{Do}_{1}-\mathrm{Do}_{2}\right) 1000\right) / \mathrm{VC}$

[SH-L]: concentración de sulfhidrilos libres en la muestra expresada como $\mu \mathrm{mol}$ de $\mathrm{SH} / \mathrm{g}$ de proteína.

$\mathrm{Do}_{1}$ : Absorbancia a $412 \mathrm{~nm}$ de la muestra

$\mathrm{Do}_{2}$ : Absorbancia a $412 \mathrm{~nm}$ del blanco de reactivos

V: volumen de la muestra

C: concentración de la proteína en la muestra

\section{Diseño experimental}

Se evaluó indirectamente el efecto térmico en las distintas posiciones (superior, central e inferior) de las muestras de las enzimas ubicadas dentro de la canasta, y los cambios producidos durante ciclos consecutivos. La variable respuesta evaluada fue la concentración de SH libres [SH-L], expresada como $\mu \mathrm{mol}$ de $\mathrm{SH} / \mathrm{g}$ de proteína. Se realizaron cuatro repeticiones del diseño. Para la evaluación de los resultados se consideró un diseño factorial de dos factores: posiciones (superior, central e inferior) y ciclo (I, II, III). El modelo estadístico utilizado fue expresado como:

$\mathrm{Y}_{\mathrm{ijk}}=\mu+\alpha_{\mathrm{i}}+\beta_{\mathrm{j}}+(\alpha \beta)_{\mathrm{ij}}+\mathrm{e}_{\mathrm{ijk}}$

con $\mathrm{i}=1,2,3 ; \mathrm{j}=1,2,3 ; \mathrm{k}=1,2$

$\mu:$ media general

$\alpha_{i}$ : efecto debido al iésimo nivel del factor posición

$\beta_{\mathrm{j}}$ efecto debido al jésimo nivel del factor ciclo

$(\alpha \beta)_{\mathrm{ij}}$ : efecto de interacción en la combinación ij

$\mathrm{e}_{\mathrm{ijk}}$ : error experimental
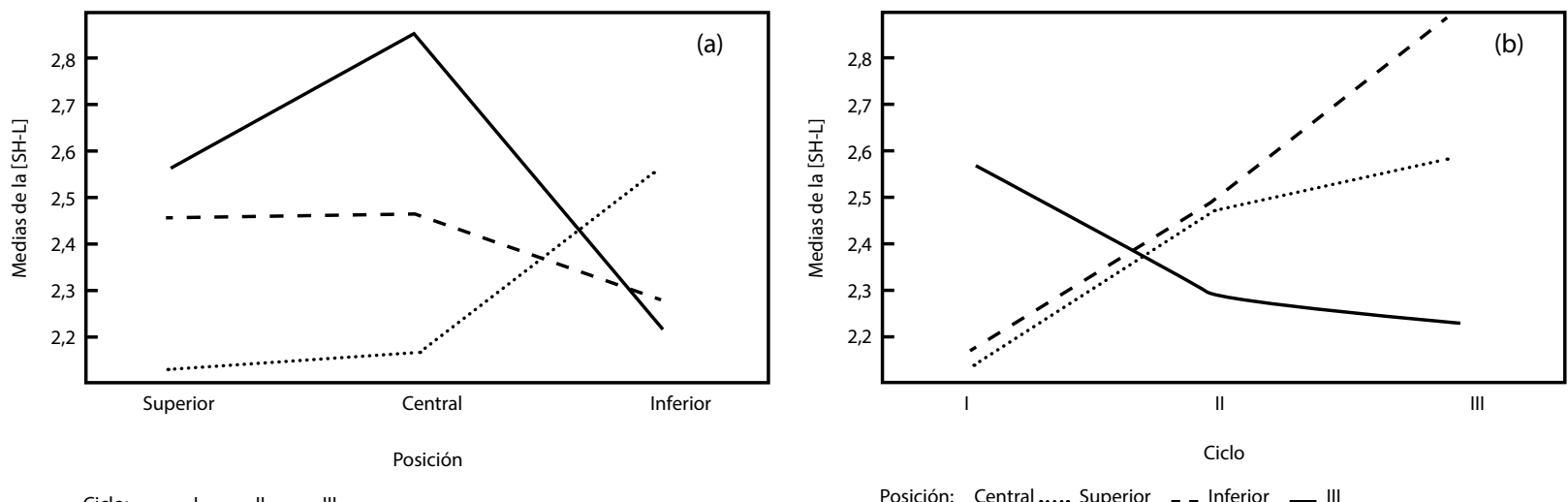

Tabla 1. Análisis de Varianza.

gl: grados de libertad

SC: suma de cuadrados

CM: Cuadrados medios

F: Estadístico F

En el Gráfico 2 se representan las curvas experimentales de presión y de temperatura en las diferentes posiciones evaluadas, y la del fluido de presurización (proceso) para los ciclos I (a), II (b) y III (c).

Se observó que el comportamiento térmico del ciclo I resultó diferente que el de los ciclos II y III, y en estos dos últimos no difirió entre sí.

En particular, en los tres ciclos de APH ensayados, las posiciones superior y central de la canasta presentaron un

Gráfico 1. Valores de medias de [SH-L] obtenidos para cada posición (a) y ciclo (b). 


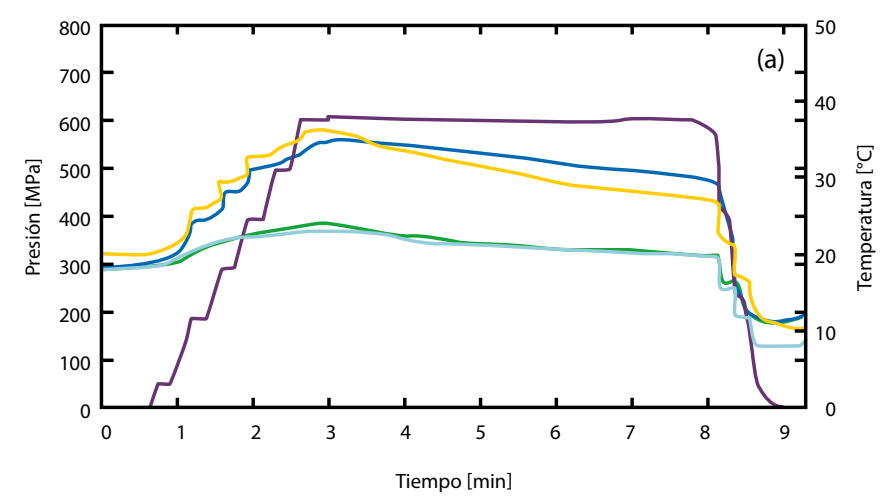

_ Presión Ciclo I _ TProceso _ T Central _ T Superior _ Tinferior

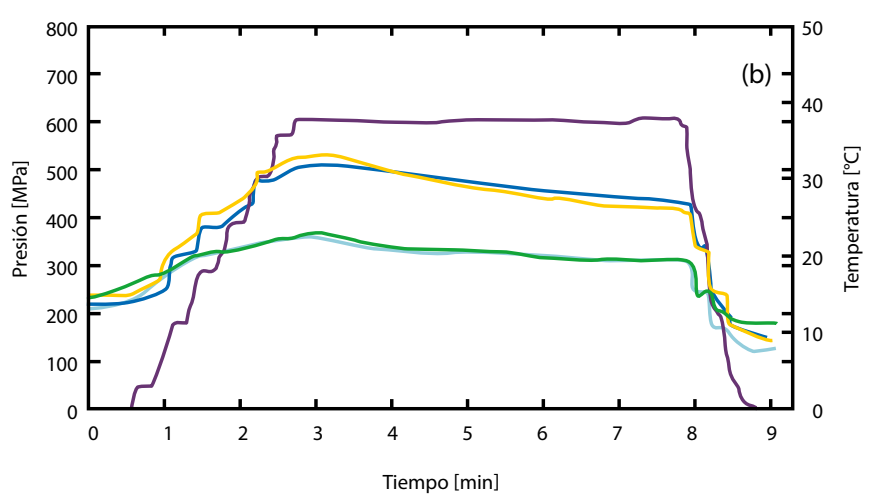

_ Presión Ciclo II - TProceso _ T Central _ T Superior _ T inferior

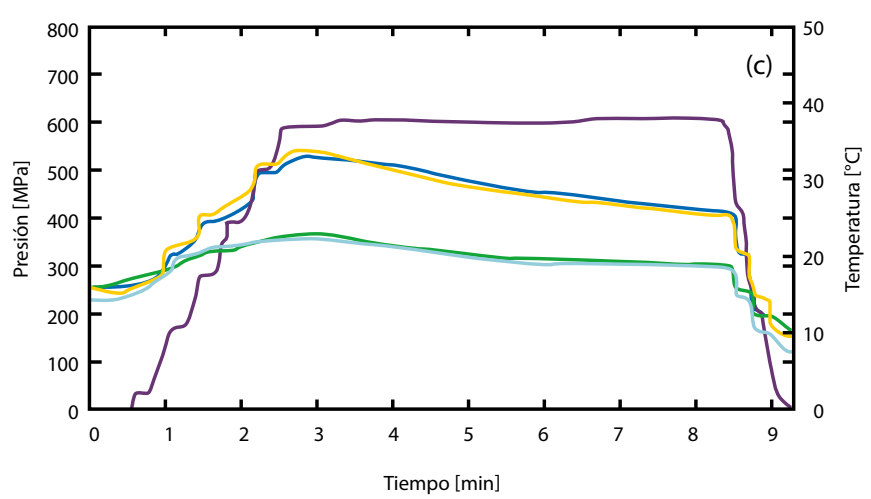

- Presión Ciclo III _ T Proceso _ T Central _ T Superior - T inferior

Gráfico 2. Evolución de la presión y temperatura en diferentes posiciones dentro del equipo de APH, para el ciclo I (a), II (b) y III (c).

mayor incremento de temperatura respecto de la posición inferior. Asimismo, se observó que el comportamiento térmico de esta última resultó ser similar al del proceso. En este sentido, Hartmann y Delgado (2003) informaron que durante la compresión se desarrolla un campo de velocidades del fluido por efecto de la convección forzada, mientras que durante la fase de mantenimiento de la presión se produce el fenómeno de convección natural. El movimiento del fluido de presurización genera condiciones térmicas no uniformes, especialmente cuando el fluido es altamente viscoso, ya que disminuye el movimiento convectivo. Si bien en la bibliografía consultada no se encontraron referencias al uso consecutivo de ciclos de APH, en este trabajo se observó que el equipo utilizado requiere como mínimo un ciclo de uso para su puesta en régimen.

En cuanto a las determinaciones de la concentración de sulfhidrilos libres [SH-L] en las posiciones superior y central, la [SH-L] aumentó con los ciclos consecutivos del equipo de $\mathrm{APH}$, mientras que para la posición inferior el comportamiento es opuesto, es decir, el valor medio de [SHL] disminuyó con los ciclos consecutivos. Esta disminución en $[\mathrm{SH}-\mathrm{L}]$ puede atribuirse a que el efecto térmico residual generado luego de los usos consecutivos del equipo provoca un menor impacto en la estructura de la molécula. Respecto a las posiciones, la más afectada fue la central, donde el valor medido de sulfhidrilos se incrementó con el aumento de los ciclos. Para el ciclo I el valor medio de [SH-L] resultó mayor en la posición inferior, luego le sucedió en orden la posición central y, por último, la posición superior. En el caso del ciclo II, la [SH-L] fue mayor en la posición central que la posición superior y ambas resultaron mayores que la posición inferior. En el ciclo III se repitió este mismo perfil, de forma aún más pronunciada. Este comportamiento es coherente con el observado en los perfiles térmicos discutidos previamente. El aumento de la temperatura del medio de presurización provoca el desplegamiento proteico, lo que se ve reflejado en el aumento de la [SH-L]. Este incremento puede ser diferente según la posición de la canasta del equipo de APH que se considere. Por su parte, Grauwet et al. (2010) evaluaron la no uniformidad térmica en equipos verticales con solo un ciclo de procesamiento de $\mathrm{APH}$ (400-600 $\mathrm{MPa} ; 10-40^{\circ} \mathrm{C}$; $1-15 \mathrm{~min}$ ) utilizando la medición de la actividad de enzimas $\alpha$-amilasas bacterianas (Bacillus subtilis), post tratamiento. Estos autores indicaron que las actividades residuales más altas (por lo tanto, los impactos del proceso más bajos) se observaron en el fondo del recipiente, donde las temperaturas son más bajas, en comparación a otras posiciones, como las centrales. El comportamiento respecto de las temperaturas concuerda con las mediciones realizadas en este trabajo. Esto puede ser atribuido a los fenómenos de convección por el flujo dirigido hacia la parte inferior del cilindro de APH. Cabe mencionar que como parámetro de evaluación del procesamiento por APH no se realizó la medición de la actividad enzimática, sino que se determinó la concentración de sulfhidrilos libres como una medida indirecta del desplegamiento proteico. En las proteínas, la presión actúa principalmente en los enlaces hidrofóbicos y electrostáticos de la molécula. La APH causa la desprotonación de los grupos cargados, la rotura de los puentes iónicos y de los enlaces hidrofóbicos, de este modo se producen cambios conformacionales y estructurales (Téllez, et al., 2001).

La metodología utilizada (pTTI's y determinación de [SH-L]) demostró ser suficientemente sensible para detectar las diferencias entre los perfiles térmicos en el equipo, permitiendo determinar un subprocesamiento de muestras, y entre los ciclos consecutivos, para monitorear la puesta en régimen.

\section{Conclusiones}

La utilización de la metodología (pTTI’s y determinación de [SH-L]) no solo permitió evaluar diferencias entre las muestras procesadas en cada posición, sino también variaciones del perfil térmico generado dentro del equipo y sus diferencias 
entre los ciclos ensayados. Se demostró que es necesario al menos dos ciclos consecutivos para que el equipo de APH entre en régimen. Los resultados obtenidos son muy prometedores y se espera continuar las investigaciones para optimizar la sensibilidad de la metodología propuesta.

\section{Referencias}

Balasubramanian, S. y Balasubramaniam, V., 2003. Compression heating influence of pressure transmitting fluids on bacteria inactivation during high pressure processing. En: Food Research International, 36, pp.661-668.

Cheftel, J., 1995. High pressure microbial inactivation and food preservation. En: Food Science Technology International, 1, pp.75-90.

Denys, S., Van Loey, A. y Hendrickx, M., 2000. A modeling approach for evaluating process uniformity during batch high hydrostatic pressure processing: combination of a numerical heat transfer model and enzyme inactivation kinetics. En: Innovative Food Science. Emerging \& Technologies,1, pp.5-19.

Ellman, G., 1959. Tissue sulfhydryl groups. En: Archives of Biochemistry and Biophysics, 82(1), pp.70-77.

Fogarty, W. y Kelly, C., 1983. Enzymic developments in the production of maltose and glucose. En: Lafferty, R.M., ed. Enzyme technology. Berlín: Springer.

Funtenberger, S., Dumay, E. y Cheftel J., 1995. Pressureinduced aggregation of $\beta$-lactoglobulin in ph 7.0 buffers. En: LWT - Food Science and Technology, 28(4), pp.410-418.

Grauwet, T., Van der Plancken, I., Vervoort, L., Hendrickx, M., y Van Loey, A., 2010. Mapping temperature uniformity in industrial scale HP equipment using enzymatic pressure-temperature-time indicators. En: Journal of Food Engineering, 98, pp.93-102.

Hartmann, Chr. y Delgado, A., 2003. The influence of transport phenomena during high-pressure processing of packed food on the uniformity of enzyme inactivation. En: Biotechnology and Bioengineering, 82(6), pp.725-35.

Hoover D G, Metrick C, Papineau A M, Farkas D F y Knorr D (1989) Biological effects of high hydrostatic pressure on food microorganisms. En: Food Technology, 43, pp.99-107.

Hugas, M., Garriga, M. y Monfort, J., 2002. New mild technologies in meat processing: high pressure as a model technology. En: Meat Science, 62, pp.359-371.

Kitsubun, P., Hartmann, C. y Delgado, A., 2005. Numerical Investigations of Process Heterogeneities during High Hydrostatic Pressure Treatment with Turbulent Inflow Conditions. En: Proc. Appl. Math. Mech., 5, pp.573-574.
Makita, T., 1992. Application of high pressure and thermophysical properties of water to biotechnology. En: Fluid Phase Equilibria, 76, pp.87-95.

Mills, E. N. C., Sancho, A. I., Rigby, N. M., Jenkins, J. A. y Mackie, A. R., 2009. Impact of food processing on the structural and allergenic properties of food allergens. En: Mol Nutr Food Res, 53, pp.963-9.

Ormando, P., Caron, P. y Larreteguy, A., 2017. Simulación hidrodinámica y térmica de un proceso a altas presiones hidrostáticas mediante OpenFOAM. En: XI Congreso Iberoamericano de Ingeniería de Alimentos, (CIBIA XI). Valparaíso, Chile, (22-25 de octubre de 2017). Valparaíso: CIBIA.

Ormando, P., Sanow, C., Vranic, M. y Vaudagna, S., 2016. Mapeo térmico durante el procesamiento por altas presiones hidrostáticas En: AIALU. II Congreso Iberoamericano de Ingeniería en Alimentos, (CIIAL 2016). Punta del Este, Uruguay, (13-14 de octubre de 2016). Punta del Este: AIALU.

Ormando, P., Sanow, C., Vranic, M., Larreteguy, A. y Vaudagna, S., 2015. Procesamiento con Altas Presiones Hidrostáticas: evaluación del incremento de temperatura del fluido en función del uso, nivel de presión y distribución dentro del equipo. En: ALACCTA. XV Congreso Argentino de Ciencia y Tecnología de Alimentos, (CyTAL 2015). Buenos Aires, Argentina (3-5 de noviembre de 2015). Buenos Aires: ALACCTA.

R Core Team, 2013. R: A language and environment for statistical computing. Viena: R Foundation for Statistical Computing.

Rasanayagam, V., Balasubramaniam, V.M., Ting, E., Sizer, C.E., Bush, C. y Anderson, C., 2003. Compression Heating of Selected Fatty Food Materials during High-pressure Processing. En: Journal of Food Science, 68, pp.254-259.

Téllez, Luis, S. J., Ramírez, J. A., Pérez Lamela, C., Vázquez, M. y Simal Gándara, J., 2001. Aplicación de la alta presión hidrostática en la conservación de los alimentos. En: Ciencia y Tecnología Alimentaria, 3(2). pp.66-80.

Van der Plancken, I., Grauwet, T., Oey, I., Van Loey, A. y Hendrickx, M., 2008. Impact evaluation of high pressure treatment on foods: considerations on the development of pressure-temperature-time integrators (pTTI's). En: Trends in Food Science \& Technology, 19, pp.337-348.

Welti-Chanes, J., López-Malo, A., Palou, E., Bermúdez, D., Guerrero-Beltrán, J. A. y Barbosa Cánovas, G. V., 2005. Fundamentals and applications of high pressure processing of foods, En: Barbosa-Cánovas G.V., Tapia M.S. y Cano M.P., eds. Novel food process technology. New York: CRC Press. pp.152-157. 